\title{
Fibrinogen St. Louis: A New Inherited Fibrinogen Variant, Coincidentally Associated with Hemophilia A
}

\author{
Laurence A. Sherman, Lamont W. Gaston, Manuel E. Kaplan, and \\ Alan R. Spivack \\ From the Department of Medicine, Jewish Hospital and Washington \\ University School of Medicine, St. Louis, Missouri 63110, and the \\ Department of Medicine, Veterans Administration Hospital, \\ Minneapolis, Minnesota 55417
}

\begin{abstract}
A B S T R A C T A patient with classical hemophilia (factor VIII deficiency) was found to have a new abnormal fibrinogen (fibrinogen St. Louis). Other family members exhibited either defect alone. Fibrinogen St. Louis was inherited as an autosomal dominant and was not associated with clinical bleeding. When compared with normal fibrinogen, fibrinogen St. Louis was found to have defective fibrin polymerization and possibly a slower release of fibrinopeptides. The prolonged thrombin times were partially corrected by calcium chloride and protamine sulfate. Ultracentrifugal sedimentation, electrophoretic mobility, DEAE chromatographic pattern, carbohydrate content, $\mathrm{N}$-terminal amino acids, immunodiffusion, and immunoelectrophoretic patterns and electrophoresis of reduced and alkylated fragments were all normal. In contrast to fibrinogen St. Louis, the most similar other fibrinogen variant (fibrinogen Zurich) was found to be heterogeneous by several criteria and to have reduced hexose content.
\end{abstract}

\section{INTRODUCTION}

In 1964, Menache reported a congenital variant of fibrinogen, which she characterized as immunologically normal but nonfunctional (nonclottable) (1). Since then, other inherited fibrinogen variants have been described (2-9), and several previous reports $(10,11)$ of hypofibrinogenemia are now believed to be qualita-

This work was presented in part at the 43rd Meeting of the Central Society for Clinical Research, Chicago, Ill., November 1970.

Dr. Gaston is a recipient of a U. S. Public Health Service Career Development Award (5-53-HE-8661) from the National Heart and Lung Institute. His present address is Department of Pathology, St. Louis University School of Medicine, St. Louis, Mo.

Received for publication 7 July 1971 and in revised form 17 September 1971. tive rather than quantitative abnormalities. The clinical concomitants of these abnormal fibrinogens have varied greatly, ranging from no clinical symptoms to bleeding tendencies. Thrombotic problems have occasionally occurred $(2,5,11)$. In several instances, wound dehiscence occurred $(1,4)$. While in most instances the functional defect has been in the polymerization phase of clot formation, in two of these variants $(1,9)$, an abnormality has existed in the enzymatic conversion by thrombin of fibrinogen to fibrin monomer. Certain physicochemical changes have served to distinguish these fibrinogen variants from normal fibrinogen and from each other. We have studied a family characterized not only by the presence of a congenital fibrinogen variant (fibrinogen St. Louis) but also by factor VIII deficiency (classical hemophilia). The biochemical and biophysical properties of the abnormal fibrinogen have been compared with previously published results of other fibrinogen variants. Direct comparisons were made between fibrinogen St. Louis, the other most similar variant-fibrinogen Zurich, ${ }^{1}$ and normal fibrinogen.

\section{METHODS}

Partial thromboplastin time (12), prothrombin time (12), thrombin time (12), fibrinogen (13), factors II (12), V (12), VII (14), and X (12), clot retraction (12), platelet factor 3 release (12), platelet adherence to glass beads (12), and platelet aggregation (12) were performed according to previously published methods. Assays for factors VIII, IX, XI, and XII were performed by a kaolin partial thromboplastin time (15) technique with congenitally deficient substrate.

Purified fibrinogen was initially prepared as the fraction I-4 of Blombäck and Blombäck (16). Because of the limited amount of plasma available from Zurich, the comparative studies between fibrinogens Zurich, St. Louis, and normal

\footnotetext{
${ }^{1}$ Kindly furnished by Dr. P. W. Straub, Zurich, Switzerland.
} 
were carried out using purified fibrinogen obtained by the method of Straughn and Wagner (17) which yielded more fibrinogen per milliliter plasma than did the method of Blombäck and Blombäck. Normal fibrinogen was prepared from the pooled plasma of four normal donors. Blood was collected as $9 \mathrm{vol} / 1 \mathrm{vol}$ of chilled $0.1 \mathrm{M}$ sodium oxalate. Coagulability was measured by a modification of the method of Laki (18). After a measured volume of fibrinogen solution was clotted with thrombin at $\mathrm{pH} 6.7$, the absorbance at $280 \mathrm{~m} \mu$ of the supernatant, nonclotted protein was determined. This was corrected for light scattering by subtracting from the absorbance at $280 \mathrm{~m} \mu, 1.7$ times the absorbance of $320 \mathrm{~m} \mu$. The absorbance of thrombin at $280 \mathrm{~m} \mu$ was also subtracted. The corrected absorbance of the noncoagulable material was divided by the corrected absorbance value for the same amount of fibrinogen not treated with thrombin. This figure multiplied times 100 was the per cent of noncoagulable protein.

Nitrogen determinations were performed by micro-Kjeldahl procedure (19) and microninhydrin technique (20). Carbohydrate analyses were performed as follows: $(a)$ hexosamine, a modified Elson-Morgan method using a glucosamine hydrochloride standard $(21) ;(b)$ hexose, by the phenol sulfuric method of DuBois, Gilles, Hamilton, Rebers, and Smith using a 1:1 mixture of galactose and mannose (22); (c) sialic acid, by the thiobarbiturate assay method of Warren (23). Absorbance coefficients were calculated on the basis of Kjeldahl nitrogens and absorbance readings at $280 \mathrm{~m} \mu$ of fibrinogen solutions dialyzed against phosphate-buffered saline. The readings were made on a Beckman DU spectrophotometer (Beckman Instruments, Inc., Fullerton, Calif.). Per cent nitrogen by weight was assumed to be $16.7 \%$ (24).

$\mathrm{N}$-terminal amino acids were determined by a previously described modification (25) of the 5-dimethylamino-1-naphthalenesulfonyl chloride (dansyl chloride) method (26).

The fibrinogens were reduced and alkylated by the method of Edelman (27), using $0.01 \mathrm{~m}$ dithiothreitol (Calbiochem, San Diego, Calif.) and 0.022 M iodoacetamide (Eastman Organic Chemicals Div., Rochester, N. Y.). The fragments were then electrophoresed on urea-starch gel with a formic acid buffer ( $\mathrm{pH} \mathrm{3.35)} \mathrm{(28).}$

Immunoelectrophoresis was performed in $0.8 \%$ agarose by the method of Wieme (29). Ouchterlony analyses were performed in agarose gels with an antigen concentration of $1.0 \mathrm{mg} / \mathrm{ml}$. Antihuman fibrinogen serum was obtained after immunizing rabbits with human fibrinogen fraction I-4 (96.4\% coagulable) in complete Freund's adjuvant. The pooled antiserum was absorbed six times with $1 / 10$ vol portions of normal human serum. The absorbed antiserum was diluted 1:2 with normal saline before use.

DEAE-cellulose gradient chromatography was performed by the method of Mosesson, Alkjaersig, Sweet, and Sherry (30) using a continuous concave gradient from $0.005 \mathrm{M}$ tris phosphate $(\mathrm{pH} 8.6)$ to $0.5 \mathrm{M}$ tris phosphate $(\mathrm{pH} 4.2)$; acrylamide gel electrophoresis by the method of Davis (31), with a $7.5 \%$ gel concentration and a tris-glycine buffer $(\mathrm{pH}$ 8.3). Ultracentrifugation was performed in a Spinco model $\mathrm{E}$ analytical ultracentrifuge with schlieren optics and a single sector cell at $56,000 \mathrm{rpm}$ and $25^{\circ} \mathrm{C}$. The sedimentation coefficients were calculated assuming a partial specific volume of $0.725 \mathrm{cc} / \mathrm{g}$.

Repolymerization of fibrin monomer was followed in a Beckman DU spectrophotometer at $350 \mathrm{~m} \mu$ using a previously described modification (30) of the method of Latallo, Fletcher, Alkjaersig, and Sherry (32). As repolymeriza- tion proceeds, light scattering results, thus increasing the absorbance at $350 \mathrm{~m} \mu$. The change in the $350 \mathrm{~m} \mu$ reading is a measure of the rate of polymerization. Fibrin polymerization times were performed by taking $0.20 \mathrm{ml}$ of a $0.5 \mathrm{~g}$ / $100 \mathrm{ml}$ fibrinogen solution, $0.04 \mathrm{ml}$ of a $0.5 \mathrm{M}$ tris-phosphate solution ( $\mathrm{pH} \mathrm{4.3)}$ and adding $0.02 \mathrm{ml}$ of a $200 \mathrm{U} / \mathrm{ml}$ bovine thrombin solution. The mixtures were then incubated at $37^{\circ} \mathrm{C}$ for $6 \mathrm{hr}$. The $\mathrm{pH}$ and ionic strength were then altered by adding $0.16 \mathrm{ml}$ of $0.1 \mathrm{M}$ sodium phosphate $\mathrm{pH}$ 6.4 , so as to permit polymerization. The time from the addition of the sodium phosphate solution until the appearance of a visible clot was recorded as the polymerization time.

The thrombin-induced release of fibrinopeptides from normal fibrinogen and fibrinogen St. Louis was measured by the method of Gaston, Lucas, and Miller (33) as the fluorescence of the C-terminal arginine (guanidino group) in alkaline ninhydrin (34). Bovine thrombin (Parke, Davis \& Co., Detroit, Mich.) was purified by DEAE-cellulose chromatography by the method of Yin and Wessler (35) and dissolved in $0.15 \mathrm{M}$ sodium chloride containing $0.1 \%$ bovine albumin (Armour Pharmaceutical Co., Chicago, Ill.). The reaction system contained $5 \mu$ moles of sodium phosphate buffer, $\mathrm{pH} 7.3 ; 1.0 \mathrm{mg}$ of fibrinogen; $0.1 \mathrm{mg}$ of soybean trypsin inhibitor (Worthington Biochemical Corp., Freehold, N. J.) ; $1.0 \mathrm{mg}$ of disodium EDTA and $0.1 \mathrm{NIH}$ $\mathrm{U}$ of thrombin in a volume of $0.5 \mathrm{ml}$. The blank tube received citrate saline and $0.15 \mathrm{M}$ saline $(0.1 \%$ in albumin) instead of fibrinogen and thrombin, respectively. Control A was stopped at zero time by the addition of $0.5 \mathrm{ml}$ of $12 \%$ trichloroacetic acid (TCA) before thrombine addition. Control $\mathrm{B}$ received $0.1 \mathrm{ml}$ of $0.15 \mathrm{M}$ saline $(0.1 \%$ in albumin) instead of thrombin. Control $\mathrm{C}$ received citrate-saline solution instead of fibrinogen. Blank and controls A, B, and $\mathrm{C}$ were incubated for $10 \mathrm{~min}$ at $37^{\circ} \mathrm{C}$. Replicate tubes containing the complete system were similarly incubated for $2,4,6,8$, and $10 \mathrm{~min}$. The reaction was stopped at the appropriate times by the addition of $0.5 \mathrm{ml}$ of $12 \%$ TCA to all tubes except control $\mathrm{A}$. The reaction mixtures were then passed through Millipore filters ( $13 \mathrm{~mm}, 0.8 \mu$, AAWP 01300) using Swinnex filter supports (Millipore SX 0001300, Millipore Corp., Bedford, Mass.). $0.18 \mathrm{ml}$ of $\mathrm{KOH}$ (to neutralize TCA), $0.32 \mathrm{ml}$ of water, $1.0 \mathrm{ml}$ of $0.5 \%$ aqueous ninhydrin, and $1.0 \mathrm{ml}$ of $1.0 \mathrm{~N} \mathrm{KOH}$ were added to $0.5 \mathrm{ml}$ of reaction mixture. After mixing, the tubes were placed in darkness for $11 \mathrm{~min}$, after which the fluorescence was read in $10 \times 75 \mathrm{~mm}$ disposable Pyrex tubes using a model 110 Turner fluorometer at $10 \times$ using Turner filters (G. K. Turner Associates, Palo Alto, Calif.) 7-60 (excitation) and 8 (emission).

Amino acids. Amino acid analysis was kindly performed by Dr. Stuart Kornfeld in a Beckman model 120C amino acid analyzer. The samples were hydrolyzed for $18 \mathrm{hr}$ in boiling $\mathrm{HCl}$ at $105^{\circ} \mathrm{C}$. By this technique, tryptophan is lost, asparagine is measured with aspartic acid, and glutamine is measured with glutamic acid.

\section{RESULTS}

The propositus, J. B., was a 55 year old white male who presented with a history of spontaneous hemarthrosis, epistaxis, and bleeding after tooth extractions. In 1966 he had viral hepatitis and the following year had the first of several episodes of upper gastrointestinal bleeding. When initially seen in April 1968, splenomegaly, mild leukopenia $\left(3200 / \mathrm{mm}^{3}\right)$, and evidence of 
liver dysfunction (reversed albumin/globulin ratio, serum glutamic oxaloacetic transaminase (SGOT) of 133 , and a bromsulphalein retention of $13 \%$ ) were noted.

Fig. 1 outlines the family tree, with the propositus, J. B., indicated by an arrow. Eight family members demonstrated the abnormal fibrinogen-four men and four women. Six other males in the family demonstrated classical factor VIII deficiency and eight of the women were carriers for classical hemophilia. No family member other than the propositus demonstrated both traits. No members of the family who had the abnormal fibrinogen, other than the propositus, demonstrated any bleeding or wound-healing abnormalities. Several persons in this group had incurred major hemostatic insults, including large lacerations, abdominal surgery, broken limbs, etc., and in no instance was hemostasis inadequate. As with the propositus, the other males in the family with factor VIII deficiency exhibited a somewhat greater bleeding tendency than would have been expected from their factor VIII levels of $8-12 \%$.

Results of the coagulation studies on J. B. are summarized in Table I. The abnormal bleeding time, fibrinogen levels, and platelet counts returned to normal after a splenectomy. (A detailed description of serial coagulation studies and clinical data of J. B. during extensive abdominal surgery-portal cava shunt and splenectomy-has been published elsewhere [36].) The half-life of plasma factor VIII after transfusion was consistent with hemophilia A rather than von Willebrand's disease. Platelet aggregation by adenosine diphosphate, thrombin, collagen, and epinephrine was normal as was platelet retention on glass beads. Other members of the family sharing the fibrinogen defect also had prolonged thrombin times of from 34.0 to $45.4 \mathrm{sec}$ (normal, 12-18 $\mathrm{sec})$. Prothrombin times ranged from 16.1 to $21.1 \mathrm{sec}$ (normal, 14-16 sec) and kaolin partial thromboplastin times were from 52.7 to $75.5 \mathrm{sec}$ (normal, $35-53 \mathrm{sec}$ ). Mixing of affected and normal plasma (1:1) only partly corrected the abnormalities. Identical fibrinogen levels were obtained by thrombin-coagulable protein, heat precipitation, and immunotiter techniques.

In Table II are summarized some of the thrombin time studies. Abnormal thrombin times were not completely corrected by a $1: 1$ mixing with normal fibrinogen. $\mathrm{CaCl}_{2}$ only partially corrected the prolonged thrombin time and also shortened the thrombin time of normal fibrinogen. The addition of protamine sulfate did not return the thrombin time to normal levels. Fibrinogen St. Louis appeared more sensitive than normal fibrinogen to $\mathrm{pH}$ changes in both acid and alkaline extremes.

\section{Coagulability}

Normal fibrinogen and fibrinogen St. Louis were 100 and $99 \%$ thrombin coagulable, respectively; whereas fibrinogen Zurich was only $80 \%$ coagulable. Immunologically, the noncoagulable $(20 \%)$ portion of Zurich protein was identified as noncoagulable fibrinogen rather than a contaminant. The incomplete coagulability of fibrinogen Zurich has been noted by von Felten, Frick, and Straub (37) using different techniques.

Polymerization studies. Repolymerization of fibrin monomer demonstrated retarded polymerization for both fibrinogen St. Louis and fibrinogen Zurich, as compared with normal (Fig. 2). Polymerization times yielded values of 31,56 , and $62 \mathrm{sec}$ for normal fibrinogen, fibrinogen St. Louis, and fibrinogen Zurich, respectively.

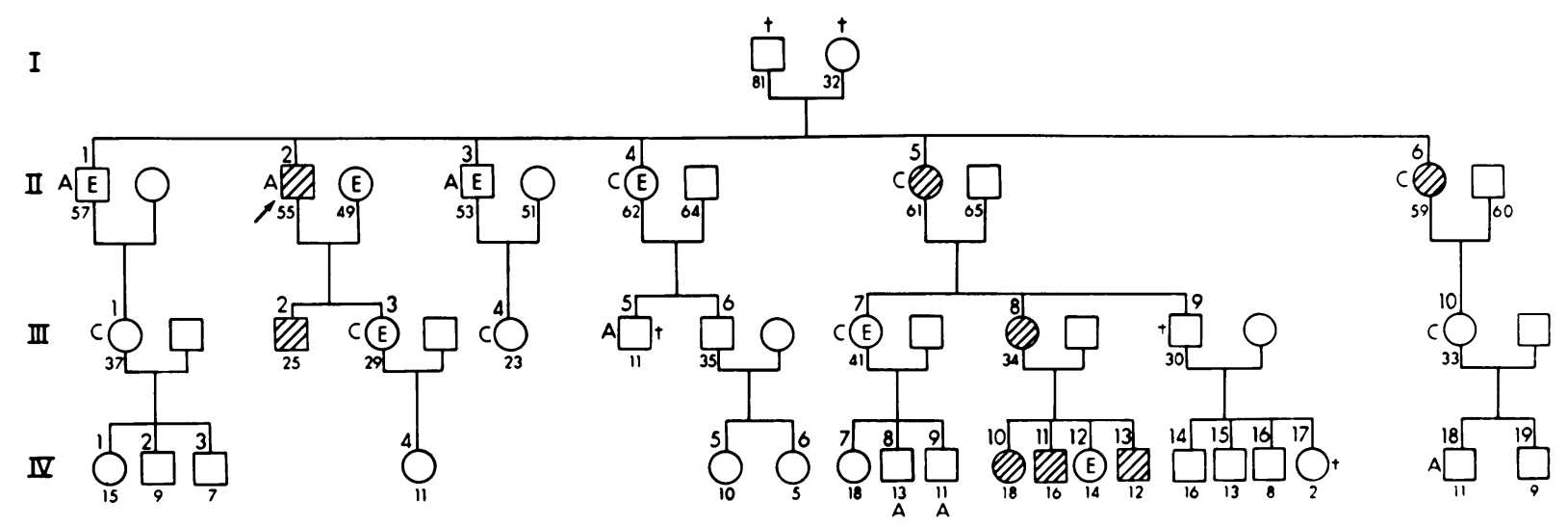

FIGURE 1 Inheritance of fibrinogen St. Louis and hemophilia in the family of J. B. The arrow indicates the proband (II-23; hatched areas, abnormal fibrinogen; A, hemophilia A; $\mathrm{C}$, carrier for hemophilia $\mathrm{A}$; E, examined with normal fibrinogen; +, deceased; subscript numerals, age. 
TABLE I

Plasma Coagulation Studies on Propositus (J. B.) and His Son (J. B., Jr.)

\begin{tabular}{lccc}
\hline \multicolumn{1}{c}{ Test } & Normal & J. B. & $(4 / 17 / 68)$ \\
\hline Bleeding time, min & 15 & 23 & J. B., Jr. \\
Prothrombin time, sec & $(14-16)$ & $25.6 / 18.0 / 15.4$ & $17.3 / 14.5 / 13.3$ \\
Kaolin partial T' plastin time, sec & $(35-53)$ & $114 / 48.8 / 34.4$ & $57.0 / 48.7 / 42.9$ \\
Thrombin time, sec & $(12-18)$ & $34.7 / 20.1 / 14.7$ & $40.1 / 19.3 / 15.9$ \\
Platelet/mm ${ }^{3}$ & $150,000-400,000$ & 96,000 & 226,000 \\
Platelet factor 3, sec & $45-60$ & 55 & 60 \\
Clot retraction & $3-7 \mathrm{~mm}$ & 3 & 4 \\
Factor I, mg 100 ml & $200-400$ & 177 & 176 \\
Factor II, \% $N$ & $75-125$ & 99 & 152 \\
Factor V, \% $N$ & $70-140$ & 120 & 84 \\
Factor VII, \% $N$ & $40-135$ & 33 & 74 \\
Factor VIII, \% $N$ & $50-200$ & 8 & 150 \\
Factor IX, \% $N$ & $60-140$ & 69 & 59 \\
Factor X, \% $N$ & $75-125$ & 45 & 120 \\
Factor XIII, \pm & + & + & + \\
\end{tabular}

Prothrombin time, partial thromboplastin time, and thrombin time results represent patient/1:1 mixture of patient and normal/normal control. $\% \mathrm{~N}$, value of sample as compared with a normal mean of $100 \%$.

TABLE II

Effect of Mixing, $\mathrm{CaCl}_{2}$, Protamine Sulfate, and of $\mathrm{pH}$ Changes on the Thrombin

Time of Normal Fibrinogen and Fibrinogen St. Louis (J. B. and J. B., Jr.)

\begin{tabular}{lc} 
Effect of mixing & \\
Plasma & Thrombin time \\
\cline { 2 - 2 } Normal & 14.7 \\
J. B. & 34.7 \\
1:1 mixture & 20.1
\end{tabular}

Effect of $\mathrm{CaCl}_{2}$

\begin{tabular}{|c|c|c|}
\hline Plasma & $\begin{array}{l}\text { Thrombin times } \\
\text { without calcium }\end{array}$ & $\begin{array}{l}\text { Thrombin times } \\
\text { with calcium }\end{array}$ \\
\hline Normal A & 13.9 & 10.4 \\
\hline Normal B & 12.1 & 10.4 \\
\hline J. B. & 48.7 & 22.9 \\
\hline
\end{tabular}

Effect of protamine sulfate

Plasma

Normal $_{1}$

$\mathrm{Normal}_{2}$

Normal $_{2}(0.025 U$ heparin/ml $)$

J. B.

J. B., Jr.

Effect of $\mathrm{pH}$

\begin{tabular}{lcrrrrrrr} 
Sample & 5.5 & 6.0 & 6.5 & 7.0 & 7.5 & 8.0 & 8.5 & 9.0 \\
Normal & 31.5 & 10.2 & 7.1 & 6.4 & 7.6 & 8.7 & 9.4 & 11.1 \\
J. B. & $>300$ & 87.5 & 45.6 & 41.1 & 51.4 & 89.6 & 155 & - \\
\hline
\end{tabular}

The mixture for studying the effect of $\mathrm{pH}$ consisted of $0.1 \mathrm{ml}$ plasma, $0.1 \mathrm{ml}$ water, $0.1 \mathrm{ml} 0.15 \mathrm{M}$ sodium phosphate, $\mathrm{pH} 5.5$ to 9.0 , and $0.1 \mathrm{ml}$ thrombin, $50 \mathrm{U} / \mathrm{ml}$ (5).

Fibrinogen St. Louis: a New Fibrinogen Variant 


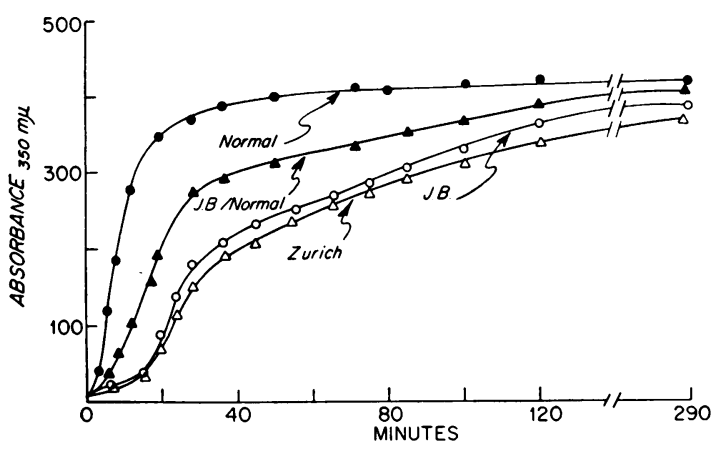

Figure 2 Polymerization of fibrin monomers from normal fibrinogen, fibrinogen St. Louis (J. B.), and fibrinogen Zurich. J. B./Normal represents a 1:1 mixture of fibrin monomers from J. B. and the normal control.

\section{Physiochemical and immunologic studies}

Ultracentrifugation. Analytical ultracentrifugation of fibrinogen St. Louis and normal fibrinogen demonstrated $S_{20 w}$ values of 7.4 and 7.5 , respectively.

Spectral analysis. The absorbancy coefficients $\left(\mathrm{A}^{\left.1 \% \%_{1 \mathrm{~m}}\right)}\right.$ at $280 \mathrm{~m} \mu$ of normal fibrinogen, fibrinogen St.
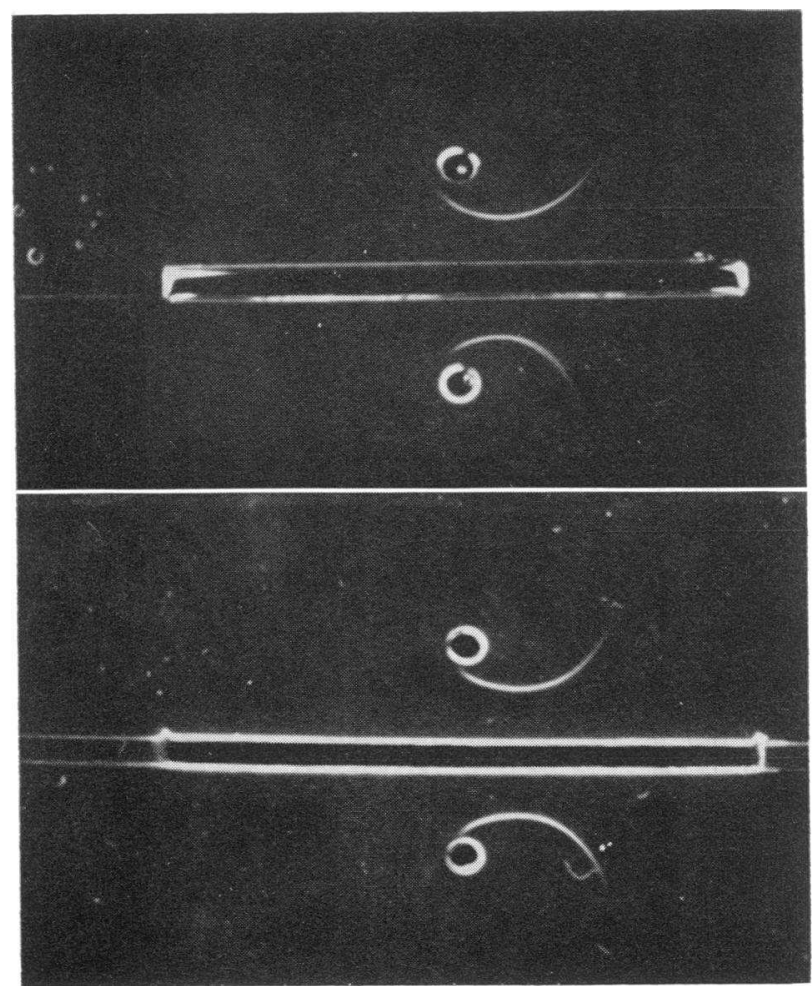

FIGURE 3 Immunoelectrophoresis of normal fibrinogen, fibrinogen St. Louis, and fibrinogen Zurich. From the top down, the wells contain fibrinogen St. Louis, fibrinogen Zurich, normal fibrinogen, fibrinogen St. Louis. The troughs in both plates contain rabbit antihuman fibrinogen serum. The anode is to the right.

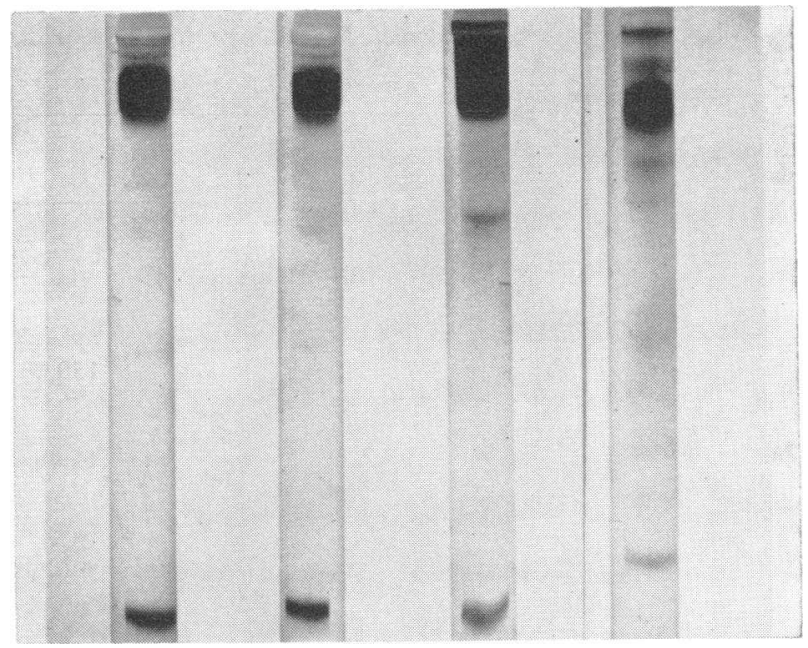

FIgURE 4 Acrylamide gel electrophoresis of normal fibrinogen, fibrinogen St. Louis, fibrinogen Zurich, and nonclottable fibrinogen Zurich. From left to right the gels represent normal, St. Louis, Zurich, and the nonclottable portion of fibrinogen Zurich.

Louis, and fibrinogen Zurich were 15.4, 16.0, and 15.9, respectively. These differences were probably not significant. The ultraviolet absorption spectra between 254 and $330 \mathrm{~m} \mu$ were essentially identical.

Electrophoresis. Immunoelectrophoresis (Fig. 3), as well as the starch gel electrophoretic patterns of the reduced and alkylated fragments revealed no differences. In acrylamide gel (Fig. 4), normal fibrinogen and fibrinogen St Louis had the same electrophoretic mobility. Fibrinogen Zurich was more heterogeneous with a broad major and distinct minor band. The noncoagulable portion of fibrinogen Zurich exhibited even more heterogeneity, with one major band and three to seven minor bands.

Immunodiffusion. On Ouchterlony analysis, normal fibrinogen, fibrinogen St. Louis, and fibrinogen Zurich all formed single lines of identity with a rabbit anti-

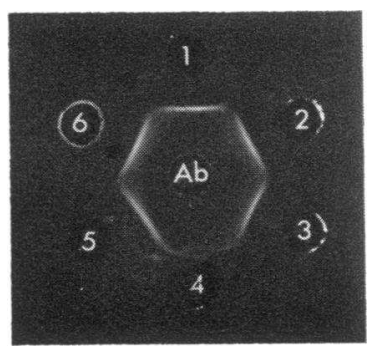

FIGURE 5 Immunodiffusion of normal fibrinogen, fibrinogen St. Louis, and fibrinogen Zurich. The outside wells contain (1) normal fibrinogen, (2) fibrinogen St. Louis, (3) fibrinogen Zurich, (4) nonclottable fibrinogen Zurich, (5) normal fibrinogen, and (6) another suspected fibrinogen variant. The center well contains rabbit antihuman fibrinogen sera. 
TABLE III

Carbohydrate Content of Normal Fibrinogen, Fibrinogen St. Louis, and Fibrinogen Zurich

\begin{tabular}{lccc}
\hline \multicolumn{4}{c}{ Carbohydrates } \\
\cline { 2 - 4 } Fibrinogen & Sialic a. & Hexosamine & Hexose \\
\hline Normal & 0.5 & 0.8 & 1.87 \\
St. Louis & 0.5 & 0.8 & 1.67 \\
Zurich & 0.5 & 0.6 & 1.15 \\
\hline
\end{tabular}

human fibrinogen serum. However, the concentrated noncoagulable fraction of fibrinogen Zurich consisted of two distinct bands (Fig. 5), the second of which appeared after $72 \mathrm{hr}$ of incubation.

$D E A E$ chromatography. On DEAE gradient chromatography, all three preparations demonstrated the same major and minor peaks of fibrinogen (peaks 1 and peaks 2) described by Mosesson and Finlayson (38). There were no significant differences in either the position on the gradient where the peaks appeared or in the relative amounts of fibrinogen in each peak.

Carbohydrate analysis. Results of carbohydrate analysis are summarized in Table III. The sialic acid content of all three fibrinogens were identical. Compared with normal fibrinogen and fibrinogen St. Louis, fibrinogen Zurich had a somewhat lower hexosamine content. This is of questionable significance. There was a significantly lower total hexose content noted in fibrinogen

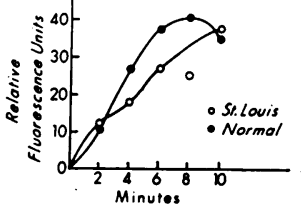

Figure 6 Release of fibrinopeptides from normal fibrinogen and fibrinogen St. Louis (J. B.). Clot formation was noted by $6 \mathrm{~min}$ with each sample.

Zurich $(1.15 \%)$ than in normal fibrinogen $(1.87 \%)$ or in fibrinogen St. Louis (1.67\%). The difference between normal fibrinogen and fibrinogen St. Louis was not significant.

$N$-terminal amino acid analysis. The N-terminal amino acids of fibrinogen St. Louis were tyrosine, alanine, and trace amounts of aspartic acid. The same results were obtained with normal fibrinogen.

Fibrinopeptide release. This assay was performed once on a sample from the propositus, J. B., and on three occasions on samples from his affected son, J. B., Jr. All the runs yielded similar results. Several different normals were used. The findings on one such determination are shown in Fig. 6. The fibrinopeptide release is expressed as relative fluorescence units. Though the rate of fibrinopeptide release from fibrinogen St. Louis was somewhat less than that released from normal fibrinogen, and was so on all four determinations, the difference may not be significant.

Amino acids. There were no significant differences between the three fibrinogens in the content of individual amino acids.

TABLE IV

Comparative Characteristics of Inherited Fibrinogen Variants

\begin{tabular}{|c|c|c|c|c|c|c|c|c|}
\hline Test & Paris & Baltimore & Zurich & Cleveland & Detroit & Bethesda & St. Louis & Paris II \\
\hline Clinical bleeding & None & Mild (TE) & None & None & Moderate & Mild & None & None \\
\hline Bleeding time & $\mathrm{N}$ & $\mathrm{N}$ & $\mathrm{N}$ & $\mathbf{N}$ & $\mathrm{N}$ & $\mathrm{N}$ & $\mathrm{N}$ & $\mathbf{N}$ \\
\hline PT & No clot & $\uparrow$ & $\uparrow$ & $\uparrow$ & $\uparrow$ & $\uparrow$ & $\uparrow$ & $\uparrow$ \\
\hline PTT & - & - & - & Sl. $\uparrow$ & $\uparrow$ & $\mathrm{N}$ & $\uparrow$ & $\uparrow$ \\
\hline TT & No clot & $\uparrow$ & $\uparrow$ & $\uparrow$ & $\uparrow$ & $\uparrow$ & $\uparrow$ & $\uparrow$ \\
\hline TT + calcium & P. C. & P. C. & P. C. & P. C. & No Corr. & - & P. C. & P. C. \\
\hline TT inhibition & Marked & None & Yes & Yes & Yes & - & Yes & Yes \\
\hline VCT & $\mathrm{N}$ & $\mathbf{N}$ & $N$ & $\mathbf{N}$ & $\uparrow$ & $\uparrow$ & $\mathrm{N}$ & $\mathrm{N}$ \\
\hline TEG & 一 & Abn. & $\mathbf{N}$ & Abn. & Abn. & - & - & Abn. \\
\hline Immunoelectrophoresis & \pm & Anodal & $\mathbf{N}$ & Anodal & Anodal & ?Abnorm. & $\mathrm{N}$ & $\mathrm{N}$ \\
\hline Immunodiffusion & $\mathbf{N}$ & $\mathrm{N}$ & $\mathbf{N}$ & $\mathrm{N}$ & Abn. & 一 & $\mathrm{N}$ & - \\
\hline DEAE chromatography & - & Abn. & 一 & 一 & 一 & $\mathrm{N}$ & $\mathrm{N}$ & Abn. \\
\hline Carbohydrate & - & $\mathrm{N}$ & $\downarrow$ & - & $\downarrow$ & - & $\mathbf{N}$ & - \\
\hline Sequence & - & - & - & - & $\alpha-19$ Arg $\rightarrow$ Ser & - & - & 一 \\
\hline Two populations & - & DEAE & FM & IE & IE & - & - & ?DEAE \\
\hline $\begin{array}{l}\text { Defect } \\
\text { Inheritance }\end{array}$ & $\begin{array}{l}\text { Enz. } \\
\text { AD }\end{array}$ & $\begin{array}{l}\text { Polym. } \\
\text { AD }\end{array}$ & $\begin{array}{l}\text { Polym. } \\
\text { AD }\end{array}$ & $\begin{array}{l}\text { Polym. } \\
\text { AD }\end{array}$ & $\begin{array}{l}\text { Polym. } \\
\text { AD }\end{array}$ & $\begin{array}{l}\text { Enz. } \\
\text { AD }\end{array}$ & $\begin{array}{l}\text { Polym. } \\
\text { AD }\end{array}$ & $\begin{array}{c}\text { Poly. ?Enz. } \\
\text { AD }\end{array}$ \\
\hline
\end{tabular}

PT, prothrombin time; PTT, partial thromboplastin time; TT, thrombin time; VCT, venous clotting time; TEG, thromboelastogram; AD, autosomal dominant; P. C., partial correction; TE, thromboembolie; FM, fibrin monomer; IE, Immunoelectrophoresis.

Because of the known heterogeneity of normal fibrinogen by several criteria, the phrase "two populations" is used to indicate unusual forms of heterogeneity in some variants. 


\section{DISCUSSION}

Family studies of fibrinogen St. Louis revealed no individual, other than the propositus, in whom both factor VIII deficiency and the abnormal fibrinogen were present. Detailed linkage studies (kindly performed by Dr. Wilma Bias) failed to reveal any associated genetic markers. Our studies with fibrinogen St. Louis clearly indicate that the protein is a genetically dominant variant characterized by a defective polymerization and there may also be an impairment in the release of fibrinopeptides. Fibrinogen St. Louis can be differentiated from previously described fibrinogen variants (Table IV). Fibrinogen Baltimore differs from fibrinogen St. Louis, the former having abnormal immunoelectrophoretic migration and DEAE-chromatographic profile. Fibrinogen St. Louis is distinguished from fibrinogen Paris and Bethesda in that the abnormality in the latter two fibrinogens is in the enzymatic phase of fibrin formation. Fibrinogen Cleveland is characterized by an abnormal immunoelectrophoretic migration. Fibrinogen Detroit has a more anodal electrophoretic migration, a decreased carbohydrate content, and does not demonstrate a shortening of the thrombin time with the addition of calcium. Fibrinogen Zurich, which resembles fibrinogen St. Louis most closely, may be distinguished from the St. Louis variant by two criteria: (a) fibrinogen Zurich's heterogeneity in coagulability, acrylamide gel electrophoresis, and immunodiffusion, and $(b)$ the decreased carbohydrate content of fibrinogen Zurich as compared with fibrinogen St. Louis. Fibrinogen Paris II (5) is characterized by a normal immunoelectrophoretic pattern, defective polymerization of fibrin monomer, and other findings similar to fibrinogen St. Louis. However, Paris II does not inhibit polymerization of normal fibrin monomer, has an abnormal DEAE-chromatographic pattern and a greater sensitivity to $\mathrm{pH}$ change than fibrinogen St. Louis. A recently reported variant, fibrinogen Amsterdam (39), is distinguished from fibrinogen St. Louis by the presence of abnormal immunoelectrophoretic mobility and defective fibrin monomer polymerization only in the presence of $\alpha-2$ globulin.

In a study of acquired dysfibrinogenemia, Mester and Szabados (40) described an increase in the sialic acid to hexosamine ratio. Similar increases have been reported in fibrinogens Paris and Detroit and is present in our results with fibrinogen Zurich (Table IV). A slight increase in this ratio has been noted in the thrombin-coagulable early derivative of plasmin-induced proteolysis of fibrinogen, both in vitro (25) and in vivo (30). However we did not find such a change in fibrinogen St. Louis and cannot fit our results into the theory of Mester and Szabados.
These data would indicate that fibrinogen St. Louis is a familial fibrinogen variant distinct from those which have been previously described. Its association with classical hemophilia is probably fortuitous. As with several other variants (3-5) there were no clinical abnormalities attributable to the abnormal fibrinogen. The principal molecular defect resides in the polymerization phase of the fibrinogen/fibrin conversion. The great variability in clinical expression of the different fibrinogen variants having defective polymerization suggests that there are various ways in which polymerization can be adversely affected and is in keeping with previous data indicating that there are a number of sites in the fibrinogen molecule which affect the polymerization process (25). The causes of different polymerization defects and why their clinical expressions vary may be of significance not only in our understanding of normal hemostasis, but also of the acquired hemostatic defects found in both primary and secondary fibrinolysis.

Note added in proof. Fibrinogen Oklahoma (Hampton, J. W. 1968. J. Lab. Clin. Med. 72: 882. [Abstr.]) was inadvertently omitted from the list of congenital variants. Fibrinogen Oklahoma has a defective response to fibrinstabilizing factor.

\section{ACKNOWLEDGMENTS}

We would like to thank Dr. J. Russell Little for performing the ultracentrifugation, Dr. Wilma Bias for performing the genetic linkage studies, and Dr. Stuart Kornfeld for performing the amino acid analyses. We also thank Miss Cynthia A. Lucas, Mr. Craig E. Miller, and Mrs. Iva Nevers for excellent technical assistance.

Supported by grants from the American and Missouri Heart Associations; Life Insurance Medical Research Foundation; and U. S. Public Health Service Grant 5-R01AM-13717 and Veterans Administration Grant TR-159.

\section{REFERENCES}

1. Menache, D. 1964. Constitutional and familial abnormal fibrinogen. Thromb. Diath. Haemorrh. Suppl. 13: 173.

2. Beck, E. A. 1964. Abnormal fibrinogen (fibrinogen Baltimore) as a cause of familial hemorrhagic disorder. Blood. 24: 853.

3. Von Felten, A., F. Duckert, and P. G. Frick. 1966. Familial disturbance of fibrin monomer aggregation. Brit. J. Haematol. 12 : 667.

4. Forman, W. B., O. D. Ratnoff, and M. H. Bover. 1968. An inherited qualitative abnormality in plasma fibrinogen: fibrinogen Cleveland. J. Lab. Clin. Med. 72: 455.

5. Samama, M., J. Soria, C. Soria, and J. Bousser. 1969. Dysfibrinogenemie congenitale et familiale sans tendance hemorragique. Nouv. Rev. Fr. Hematol. 9: 817.

6. Mammen, E. F., A. S. Prasad, M. I. Barnhart, and C. C. Au. 1969. Congenital dysfibrinogenemia: fibrinogen Detroit. J. Clin. Invest. 48: 235.

7. Verstraete, M., Cited by E. A. Beck, M. W. Mosesson, P. Charache, and D. P. Jackson. 1966. Hamorrhagische Diathese mit dominantem Erbgang, verursacht durch ein anomales Fibrinogen (fibrinogen Baltimore). Schweiz. Med. Wochenschr. 96: 1196. 
8. Zietz, B. H., and J. L. Scott. 1970. An inherited defect in fibrinogen polymerization: fibrinogen Los Angeles. Clin. Res. 18: 179. (Abstr.)

9. Gralnick, H. R., H. Givelber, and J. S. Finlayson. 1970. A familial bleeding disorder associated with dysfibrinogenemia (fibrinogen Bethesda). Clin. Res. 18: 405. (Abstr.)

10. Imperato, D. C., and A. G. Dettori. 1958. Ipofibrinogenemia congenita con fibrinoastenia. Helv. Paediat. Acta. 13: 380 .

11. Hasselback, R., B. Marion, and J. W. Thomas. 1963. Congenital hypofibrinogenemia in five members of a family. Can. Med. Ass. J. 88: 19.

12. Gaston, L. W., J. E. Brooks, H. J. Blumenthal, and C. E. Miller. 1971. A study of blood coagulation following an acute stroke. Stroke. 2: 81.

13. Ratnoff, O. C., and C. Menzie. 1951. A new method for the determination of fibrinogen in small samples of plasma. J. Lab. Clin. Med. 37: 316.

14. Gaston, L. W., and A. R. Spivak. 1968. Preparation of canine factor VII deficient substrate plasma. J. Lab. Clin. Med. $72: 548$.

15. Proctor, R. R., and S. I. Rapaport. 1961. The partial thromboplastin time with kaolin. Amer. J. Clin. Pathol. $36: 212$.

16. Blombäck, B., and M. Blombäck. 1956. Purification of human and bovine fibrinogen. Ark. Kemi. 10: 415.

17. Straughn, W., III, and R. H. Wagner. 1966. A simple method for preparing fibrinogen. Thromb. Diath. Haemorrh. 16: 198.

18. Laki, K. 1951. The polymerization of proteins: the action of thrombin on fibrinogen. Arch. Biochem. Biophys. 32: 317.

19. Chase, M. W., and C. A. Williams. 1968. Chemical analyses. Determination of nitrogen by the Kjeldahl method. In Methods in Immunology and Immunochemistry. C. A. Williams and M. W. Chase, editors. Academic Press, Inc., New York. 2 : 257.

20. Schiffman, G., E. A. Kabat, and W. Thompson. 1964. Immunochemical studies on blood groups $\mathrm{XX}$ : cleavage of $\mathrm{A}, \mathrm{B}$, and $\mathrm{H}$ blood-group substances by alkali. Biochemistry. 3 : 113.

21. Kabat, E. A. 1961. Hexosamine and N-acetyl hexosamine estimation. In Experimental Immunochemistry. E. A. Kabat and M. M. Mayer, editors. Charles C. Thomas, Publisher, Springfield. 2nd edition. 504

22. DuBois, M., K. A. Gilles, P. A. Hamilton, P. A. Rebers, and F. Smith. 1956. Colorimetric method for determination of sugars and related substances. Anal. Chem. 28: 350 .

23. Warren, L. 1959. The thiobarbituric acid assay of sialic acid. J. Biol. Chem. 234 : 1971.

24. Schultze, H. E., and J. F. Heremans. 1966. Molecular Biology of Human Proteins. American Elsevier Publishing Co., Inc., New York. 218.

25. Sherman, L. A., M. W. Mosesson, and S. Sherry. 1969. Isolation and characterization of the clottable low molec- ular weight fibrinogen derived by limited plasmin hydrolysis of human fraction I-4. Biochemistry. 8: 1515.

26. Gray, W. R., and B. S. Hartley. 1963. A fluorescent end group reagent for proteins and peptides. Biochem. J. 89: 59P. (Abstr.)

27. Edelman, G. M., W. E. Gall, M. J. Waxdal, and W. H. Konigsberg. 1968. The covalent structure of a human gamma G-immunoglobulin. I. Isolation and characterization of the whole molecule, the polypeptide chains, and the tryptic fragments. Biochemistry. 7: 1950.

28. Poulik, M. D. 1968. Electrophoresis. Starch gel electrophoresis. In Methods in Immunology and Immunochemistry. C. A. Williams and M. W. Chase, editors. Academic Press. Inc., New York. 2: 25.

29. Wieme, R. J. 1959. An improved technique of agar gel electrophoresis on microscopic slides. Clin. Chim. Acta. 4: 317.

30. Mosesson, M. W., N. Alkjaersig, B. Sweet, and S. Sherry. 1967. Human fibrinogen of relatively high solubility. Comparative biophysical, biochemical, and biological studies with fibrinogen of lower solubility. Biochemistry. $6: 3279$.

31. Davis, B. J. 1964. Disc electrophoresis II : method and application to human serum proteins. Ann. N. Y. Acad. Sci. 121 : 404.

32. Latallo, Z. S., A. P. Fletcher, N. Alkjaersig, and S. Sherry. 1962. Influence of $\mathrm{pH}$, ionic strength, neutral ions and thrombin on fibrin polymerization. Amer. J. Physiol. 202: 675 .

33. Gaston, L. W., C. A. Lucas, and C. E. Miller. 1969. A fluorometric assay for thrombin. J. Lab. Clin. Med. 74: 874. (Abstr.)

34. Conn, R. B., Jr., and R. B. Davis. 1959. Green fluorescence of guanidinium compounds with ninhydrin. Nature (London). 183: 1053.

35. Yin, E. T., and S. Wessler. 1968. Bovine thrombin and activated factor X. Separation and purification. J. Biol. Chem. 243: 112.

36. Gaston, L. W., A. E. Baue, D. A. Pfaff, and L. Wise. 1971. Spleno-renal shunt, cholecystectomy and appendectomy in a patient with hemophilia $\mathrm{A}$, an abnormal fibrinogen and thrombocytopenia. Ann. Surg. 173: 234.

37. von Felten, A., P. G. Frick, and P. W. Straub. 1969. Studies on fibrin monomer aggregation in congenital dysfibrinogenemia (fibrinogen "Zurich"): separation of a pathological from a normal fibrin fraction. Brit. $J$. Haematol. 16: 353.

38. Mosesson, M. W., and J. Finlayson. 1963. Heterogeneity of human fibrinogen. Biochemistry. 2: 42.

39. Janssen, C. L., and J. Vreeken. 1971. Fibrinogen Amsterdam, another hereditary abnormality of fibrinogen. Brit. J. Haematol. 20 : 287.

40. Mester, L., and L. Szabados. 1970. Structure defecteuse et biosynthese des fractions glucides dans les variantes pathologiques du fibrinogene. Nouv. Rev. Fr. Hematol. 10 : 679 . 